\title{
LA-ICP-MS анализ бадделеита, циркона и сульфидов из пород комплексных месторождений Фенноскандинавского щита в пределах Арктического региона
}

\author{
Дрогобужская С.В. ${ }^{1}$, Баянова Т.Б. ${ }^{2}$, Новиков А.И. ${ }^{1}$, Нерадовский Ю.Н. ${ }^{2}$, Субботин В.В. ${ }^{2}$, \\ Савченко Е.Э. ${ }^{2}$ \\ ${ }^{1}$ Институт химии и технологии редких элементов и минерального сырья им. И.В. Тананаева КНЦ \\ PAH, Anamumbl,Drogo_sv@chemy.kolasc.net.ru \\ ${ }^{2}$ Геологический институт КНЦ РАН, Anamumbl, bayanova@geoksc.apatity.ru
}

Аннотация. В статье даётся обзор новых разработанных методик определения in situ концентраций и распределений REE, Hf, U, Th, Y, Ti, в минеральных зернах циркона и бадделеита, а так же REE, PGE и других сидерофильных и халькофильных элементов в сульфидах методом LA-ICP-MS. Впервые приведены результаты LA-ICP-MS измерений большого числа элементов в цирконе, бадделеите и сульфидах, выделенных из пород комплексных месторождений Фенноскандинавского щита в пределах Арктического региона.

Ключевые слова: LA-ICP-MS, бадделеит, циркон, сульфиды, REE, PGE, комплексные месторождения.

\section{LA-ICP-MS analysis of baddeleyite, zircon, sulfides from rocks of the Fennoscandiand Shield complex deposits in the Arctic region}

\author{
Drogobuzhskaya S.V. ${ }^{1}$, Bayanova T.B. ${ }^{2}$, Novikov A.I. ${ }^{1}$, Neradovskiy Yu. ${ }^{2}$, Subbotin V.V. ${ }^{2}$, Savchenko E.E. ${ }^{2}$ \\ ${ }^{1}$ Tananaev Institute of Chemistry KSC RAS , Apatity,_Drogo_sv@chemy.kolasc.net.ru \\ ${ }^{2}$ Geological institute KSC RAS, Apatity, bayanova@geoksc.apatity.ru
}

\begin{abstract}
The paper reviews new methods for in situ determination of concentrations and distributions of REE, Hf, U, Th, Y, Ti in mineral grains of zircon and baddeleyite, as well as REE, PGE and other siderophilic and chalcophilic elements in sulfides, by the LA-ICP-MS technique. For the first time, results of LA-ICP-MS estimations of many elements in zircon, baddeleyite and sulfides from rocks of complex deposits of the Fennoscandian Shield of the Arctic region.
\end{abstract}

Key words: LA-ICP-MS, baddeleyite, zircon, sulfides, REE, PGE, complex deposits.

\section{Введение}

Современные методы локального анализа, в том числе масс-спектрометрия с индуктивно связанной плазмой с лазерной абляцией (LA-ICP-MS), позволяют проводить изучение in situ минеральных зерен. Метод достаточно распространен в зарубежной практике, но мало используется в российских лабораториях, позволяет проводить анализ ультрамалой массы вещества, отбираемой с помощью лазерной установки и одновременно определять большое число элементов с низкими пределами обнаружения. Так как зёрна минералов часто имеют малые размеры (около 100 мкм) и внутреннюю неоднородность строения (зональность, секториальность, дефектность и включения) возникает необходимость применения локальных методов анализа.

Исследования минералов методом LA-ICP-MS основаны на измерениях концентраций и распределений изотопов редких элементов в отдельных зернах или их фрагментах. На экспериментальных данных по геохимии редких и рассеянных элементов базируются исследования в области строения и истории формирования земной коры и мантии, процессов миграции элементов. Наиболее интересны акцессорные минералы циркон и бадделеит для изучения распределений редких и редкоземельных элементов (REE), а также пирит, пентландит, пирротин и другие сульфиды для определения элементов платиновой группы (PGE), REE и др.

Для циркона изучение микроэлементного состава является широко применяемой практикой (Belousova E.A. et al., 2002; Hanchar E. et al., 2003). Бадделеит также является важным минералом, но менее распространенным, его геохимические характеристики изучены мало. Первые данные по определению концентраций и распределений REE в бадделеите были опубликованы в прошлом 
веке (Reishmann et al., 1995). Бадделеит используют как минерал-геохронометр для прецизионного U-Pb датирования основных и щелочных пород (Баянова Т.Б., 2004, 2006; Rubatto D. et al., 2003). Можно отметить, что данные по его геохимическому составу весьма противоречивы, сильно варьирует величина $C e$-аномалии, в ряде данных отсутствует $E$-аномалия и работ, касающихся геохимии бадделеита, существенно меньше.

Информация о содержании PGE, Au и Ag в сульфидах, включая данные об их распределении в минералах, важна для изучения источников происхождения благородных металлов в сульфидных рудах и понимания условий формирования комплексных месторождений. Определение концентраций других элементов-примесей (Cu, $\mathrm{Co}, \mathrm{Ni}, \mathrm{As}, \mathrm{Sb}, \mathrm{Se}, \mathrm{Te}, \mathrm{Bi}, \mathrm{Sn}$ и REE) существенно дополняет геохимические данные. Однако отечественная практика применения LA-ICP-MS для решения данных задач не столь широка (Митрофанов и др., 2013; Викентьев И.В. и др., 2016).

Целью геохимических исследований являлось определение концентраций и распределений $\mathrm{REE}, \mathrm{Hf}, \mathrm{U}, \mathrm{Th}, \mathrm{Y}, \mathrm{Ti}, \mathrm{PGE}$ и других элементов в акцессорных минералах, выделенных из комплексных месторождений Арктического региона Фенноскандинавского щита с использованием локального анализа микропримесей LA-ICP-MS.

\section{Методика исследования}

Для исследования морфологии образцов использовали метод электронной (LEO-1415) и оптической (LEICA OM 2500 P, камера DFC 290) спектроскопии, местоположение локального анализа на кристаллах выбирали на основании анализа их BSE и CL-изображений. Измерения REE, PGE и других элементов in situ проводили методом ICP-MS на квадрупольном масс-спектрометре ELAN 9000 DRC-e (Perkin Elmer) с использованием лазерного испарителя UP-266 MACRO (New Wave Research) с длиной волны 266 нм. Лазерную абляцию циркона и бадделеита проводили в атмосфере аргона в точке диаметром 35-100 мкм или при сканировании «в линию» шириной 35-70 мкм с контролем геометрических параметров полученных кратеров, частотой повторения импульсов 10 Гц (длительность импульса 4 нс) и энергией в импульсе 14-15 Дж/см². Для получения градуировочной зависимости с расширенным диапазоном измерений до 3-4 порядков использовали силикатный образец NIST SRM 612 с известной концентрацией REE, U, Th, Ti, и Hf порядка 40 ppm, а для проверки правильности измерений - образец NIST SRM 610 с концентрацией около 450 ppm. Для расширения диапазона линейности при построении градуировочной зависимости изменяли диаметр лазерного пучка при постоянстве остальных параметров: от 35 до 240 мкм (точечный пробоотбор) и от 20 до 155 мкм при сканировании «в линию» $(r=0.999)$. Для всех определяемых элементов среднее квадратичное отклонение (СКО) по градуировочным стандартам не превышало 15 \%. Предел определения концентраций изучаемых микроэлементов $0.01 \mathrm{ppm}$ достигнут при диаметре лазерного пучка 155 мкм, что сопоставимо с имеющимися данными (Yuan H. et al., 2004). Правильность методики основана на результатах измерений международных стандартных образцов циркона 91500, TEMORA 1, Mud Tank и межлабораторной воспроизводимости (Николаев А.И. и др., 2016).

Измерения PGE, REE и других элементов ( $\mathrm{S}, \mathrm{Cr}, \mathrm{Fe}, \mathrm{Cu}, \mathrm{Ni}, \mathrm{Co}, \mathrm{As}, \mathrm{Se}, \mathrm{Mo}, \mathrm{Cd}, \mathrm{Sn}, \mathrm{Sb}, \mathrm{Re}, \mathrm{Ti}$, $\mathrm{Te}, \mathrm{Tl}, \mathrm{Hf}, \mathrm{W}, \mathrm{Bi}, \mathrm{Pb}, \mathrm{Th}, \mathrm{U}$ ) в сульфидах проводили в атмосфере аргона или гелия в точке диаметром от 35 до 155 мкм с частотой повторения импульсов 7 и 10 Гц и энергией в импульсе 3.0-3.5 мДж. Для градуировки прибора использовали NIST 610, NIST 612 и тандемную градуировку (по растворам) с учетом коэффициентов чувствительности изотопов. Значения концентраций элементов в стандартах получены из сертификата NIST и данных работ (Jochum K.P. et al., 2011; Pearce N.J.G., 1997). В качестве внутреннего стандарта использовали железо как самый равномерно распространенный элемент в сульфидных минералах. Для проведения нормирования по матричному элементу предварительно были подготовлены и проанализированы с помощью микрозонда (Сameca MS-46) основные элементы в эталонных образцах халькопирита, пентландита и пирротина. Проведенные измерения макроэлементов в сульфидных минералах методом LA-ICP-MS отразили хорошую воспроизводимость с данными микрозонда (средние значения для кристалла халькопирита - S - 35.2 и $35.1 \%$; $\mathrm{Fe}-30.2$ и $30.3 \% ; \mathrm{Cu}-34.2$ и $34.5 \%$ для LA-ICP-MS и микрозонда соответственно). При проведе- 
нии измерений родия и рутения в халькопирите и пентландите были учтены интерференции меди и никеля.

\section{Полученные результаты}

Новые разработанные методики были использованы для определения REE, U, Th, Ti, и Hf в цирконе, выделенном из основных и кислых гранулитов и гранат-амфиболовых гнейсов Лапландского пояса, внутригранитных пегматитов Кейвской зоны, габбро-анортозитов Кандалакшской и Колвицкой зоны, из жильных пегматитов габброноритового состава $\mathrm{Cu}-\mathrm{Ni}$ месторождения Терраса, г. Нюд Мончегорского плутона (Николаев А.И. и др., 2016; Стешенко Е.Н., 2017, 2018). Концентрации титана в зернах циркона были использованы для расчета температуры кристаллизации акцессорных минералов и закрытия U-Pb-системы по методике (Watson et al., 2006).

Бадделеит (кристаллы и фрагменты) был выделен из пород расслоенных ЭПГ интрузий в Мончегорском рудном узле (из средне-крупнозернистого лейкогабронорита и габбронорит-анортозита с $\mathrm{Pt}-\mathrm{Pd}$ рудопроявлениями, из жильных пегматитов габброноритового состава $\mathrm{Cu}-\mathrm{Ni}$ месторождения Терраса, г. Нюд,) и карбонатитов Ковдора и Вуориярви. Результаты определения микроэлементов в разных зернах циркона и бадделеита, нормированные на хондрит, приведены на рисунке 1.

В таблице 1 приведены диапазоны концентраций перечисленных элементов в зернах бадделеита, выделенных из реперных пород комплексных месторождений.

Таблица 1. Концентрации REE, Hf, U, Th, Ti, Y в бадделеите из реперных пород комплексных месторождений.

Table 1. Concentrations of REE, Hf, U, Th, Ti, Y in baddeleyite from reference rocks of multimetal deposits.

\begin{tabular}{|c|c|c|c|c|c|c|c|c|c|}
\hline \multirow{2}{*}{$\begin{array}{l}\text { Место } \\
\text { отбора }\end{array}$} & \multirow{2}{*}{$\begin{array}{l}\frac{\pi}{0} \\
\text { ㅇ } \\
\text { Oे }\end{array}$} & \multirow{2}{*}{ Проба } & \multirow{2}{*}{$\begin{array}{c}\text { Возраст, } \\
\text { лет }\end{array}$} & \multicolumn{6}{|c|}{ Концентрации элементов, ppm } \\
\hline & & & & Hf, $\%$ & $\mathrm{Ti}$ & Th & $\mathrm{U}$ & $\mathrm{Y}$ & $\Sigma \mathrm{REE}$ \\
\hline \multirow{3}{*}{$\begin{array}{c}\text { Мончегорский } \\
\text { плутон }\end{array}$} & 1 & 09-3 1-106 & \multirow{3}{*}{2.5 млр. } & $0.30-0.75$ & $469-1212$ & $2.8-73.8$ & $68.2-213$ & $230-849$ & $239-772$ \\
\hline & 2 & 09-3 7-106 & & $0.14-0.56$ & $260-879$ & $12.6-32.9$ & $58.2-114$ & $109-336$ & $144-291$ \\
\hline & 3 & M-2 & & $0.30-1.79$ & $940-6015$ & $2.8-27.6$ & $136-1057$ & 20.4-133 & $18.1-150$ \\
\hline Вуори-ярви & \multirow{3}{*}{4} & $\mathrm{Bd} 400$ & \multirow{3}{*}{380 млн. } & $0.14-1.98$ & $69.3-623$ & $0.83-15.8$ & $2.5-48.1$ & $5.4-65.9$ & $19.5-103$ \\
\hline \multirow{2}{*}{ Ковдор } & & Bd 300 & & $0.098-0.91$ & $10.7-92.2$ & $0.04-6.7$ & $2.7-76.2$ & $2.2-27.3$ & $2.1 .5-18.5$ \\
\hline & & $\begin{array}{c}\text { Bd } 300 \\
\text { призмат }\end{array}$ & & $0.19-1.33$ & $28.0-72.1$ & $0.68-1.6$ & $4.2-21.3$ & $2.2-9.5$ & $11.1-17.7$ \\
\hline
\end{tabular}

1 - средне-крупнозернистый лейкогабронорит, 2- габбронорит-анортозит, 3 - пегматиты габброно-ритового состава, 4 - карбонатиты.
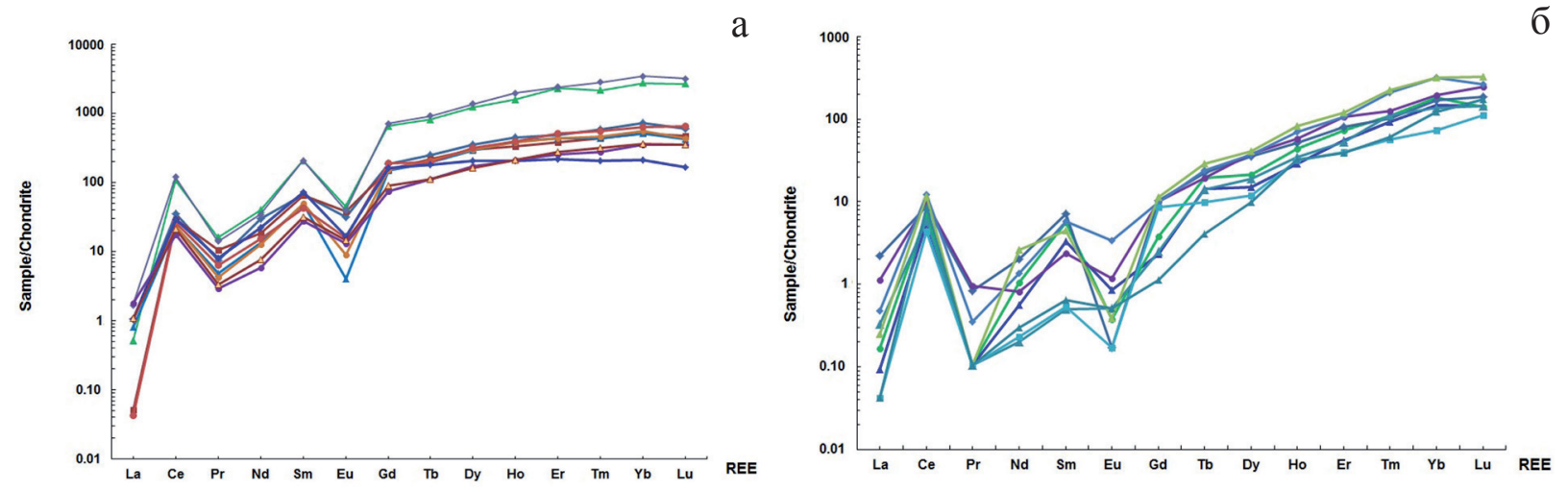

Рис. 1. Распределение REE, нормированных на хондрит (McDonough W. F., Sun S-S., 1995) в цирконе (а) и бадделеите (b), выделенных из жильных пегматитов габброноритового состава $\mathrm{Cu}-\mathrm{Ni}$ месторождения Терраса, г. Нюд.

Fig. 1. Chondrite normalised REE distribution on zircon (a) and baddeleyite (b) from pegmatites vein of gabbronorite composition Cu-Ni Terrace deposit, Nyud Mt. (McDonough W. F., Sun S-S., 1995). 

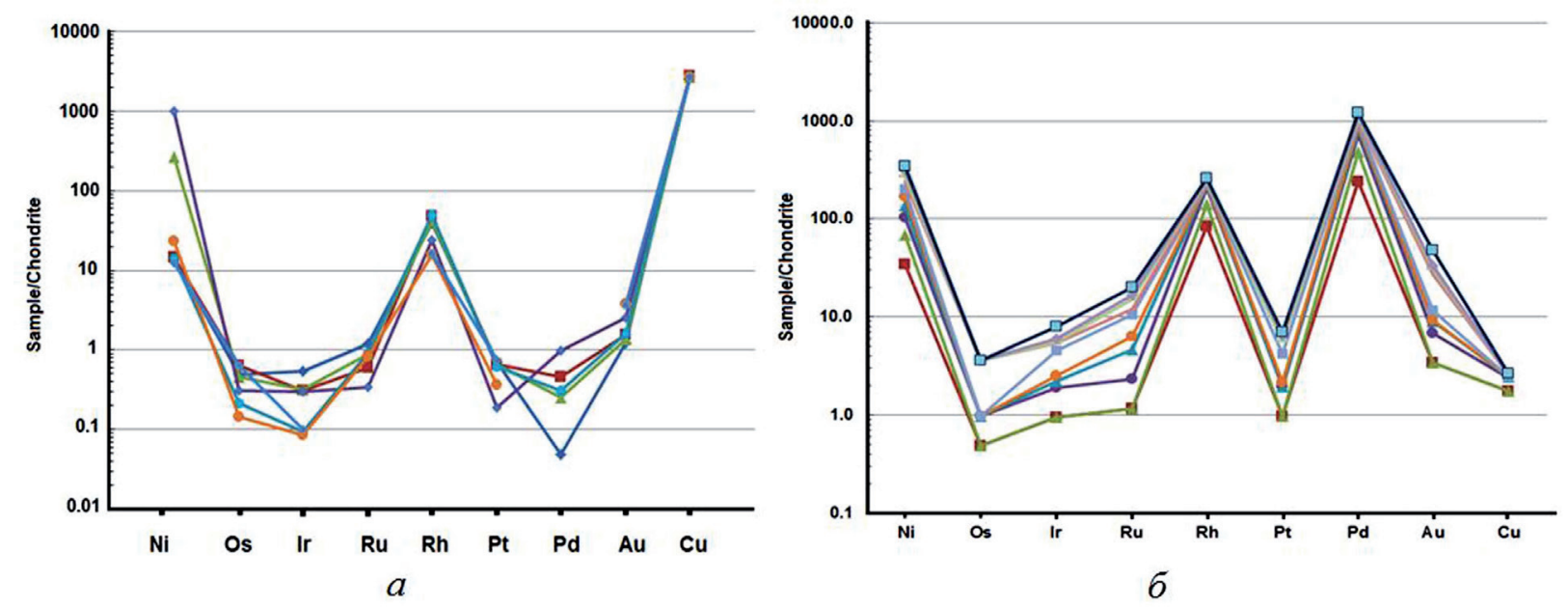

Рис. 2. Распределение PGE, Au, Cu и Ni в халькопирите (a) (Печенга) и пентландите (b) (м. Аллареченское), нормированные на хондрит (McDonough W. F., Sun S-S., 1995).

Fig. 2. Chondrite-normalised PGE, Au, Cu and Ni distribution in chalcopyrite (a) (Pechenga) and pentlandite (b) (M. Allarechenskoye) (McDonough W. F., Sun S-S., 1995).

Методики LA-ICP-MS были использованы для определения in situ благородных металлов (PGE, $\mathrm{Au}, \mathrm{Ag}$ ) и халькофильных элементов в сульфидных минералах с целью изучения их распределений в халькопирите, пентландите, пирите $\mathrm{Cu}-\mathrm{Ni}$ месторождений Печенгское и Аллареченское, и PGE месторождений Федорова тундра и Северный Каменник.

В халькопирите (Печенга) отражено равномерное распределение $\mathrm{Ti}, \mathrm{Cr}, \mathrm{Mn}, \mathrm{Cd}, \mathrm{Sn}, \mathrm{Te}, \mathrm{Pb}$, концентрации которых измерены на уровне первых десятков ppm. Можно отметить, что из платиновых металлов, Rh и Pt распределены более равномерно, концентрация которых варьируют от 0.65 до $2.0 \mathrm{ppm}$ и от 0.54 до $3.8 \mathrm{ppm}$ соответственно, крайне неравномерно по минералу распределен Os и $\mathrm{Ru}$ (от 0.02 до 0.9 ppm). Массовая доля Pd составляет 0.29-2.3; $\mathrm{Ir}-0.29-1.75 ; \mathrm{Ag}-0.08-1.45$; $\mathrm{Au}-0.16-6.6 \mathrm{ppm}$, концентрация Re в образце - 0.17-1.3 ppm.

Халькопирит (Федорова тундра) отличается повышенным содержанием $\mathrm{Se}(0.03-0.05 \%)$ и $\mathrm{Ni}(0.4-0.5$ \%). В халькопирите (уч. Чурозерский), в котором встречаются минералы PGE (сперрилит), в отдельных точках обнаружено рекордное количество $\mathrm{Ag}$ (n, \%). В пентландите (м. Аллареченское) относительно равномерно распределено только $\mathrm{Ag}$ (1.7 ppm - сред.), диапазон концентраций PGE аналогичен халькопириту (уч. Чурозерский), массовая доля Se составляет $40 \mathrm{ppm}$. На рисунке 2 представлены распределения PGE, Cu и Ni в халькопирите (Печенга) и пентландите (м. Аллареченское), нормированные на хондрит (Sun S.S et al., 1989).

Методом LA-ICP-MS в сульфидных минералах впервые определены также in situ концентрации REE. В зернах халькопирита (Печенга) измерены концентрации REE от 1.45 до 15.3 ppm, доля лёгких LREE и тяжелых HREE соизмерима.

Таким образом, новые разработанные методики LA-ICP-MS позволяют проводить измерения концентраций и распределений REE, Hf, U, Th, Ti, Y в минеральных зернах циркона и бадделеита, а также PGE и др. сидерофильных и халькофильных элементов в сульфидах, что показано на примере анализа минералов, выделенных из пород комплексных месторождений Фенноскандинавского щита в пределах Арктического региона.

Работа выполнена в рамках темы НИР № 0226-ИХ-2018-0002, 0226-2019-0053, частично поддержана из средств гранта РФФИ (18-05-70082 Ресурсы Арктики) и Программы Президиума РАН 1.48.

\section{Литература}

1. Баянова Т.Б. Возраст реперных геологических комплексов Кольского региона и длительность процессов магматизма, СПб. Наука. 2004.174 с. 
2. Баянова Т.Б. Бадделеит - перспективный геохронометр щелочного и базитового магматизма // Петрология. 2006. 14. № 2. С. 203-216.

3. Викентьев И.В., Абрамова В.Д., Иванова Ю.Н., Тюкова Е.Э., Ковальчук Е.В., Бортников Н.С. Микропримеси в пирите золото-порфирового месторождения Петропавловское (Полярный Урал) по данным LA-ICP-MS // Докл. Академии наук. 2016. Т. 470. № 3. С. 326-330.

4. Николаев А.И., Дрогобужская С.В., Баянова Т.Б. Каулина Т.В., Лялина Л.М., Новиков А.И., Стешенко Е.Н. Изучение распределений REE в цирконе реперных пород Арктики методом LA-ICP-MS // Докл. Академии наук. 2016. Т. 470. № 4. С. 448-452.

5. Митрофанов А.Ф., Когарко Л.Н., Аносова М.О., Костицын Ю.А. Особенности распределения благородных металлов в сульфидных парагенезисах месторождения Федорова тундра (Кольский п-ов) // Докл. Академии наук. 2013. 451. № 6. С. 676.

6. Стешенко Е.Н., Николаев А.И., Баянова Т.Б., Дрогобужская С.В., Чащин В.В., Серов П.А., Лялина Л.М., Новиков А.И. Палеопротерозойский Кандалакашский анортозитовый массив: новые данные о возрасте (U-Pb, ID-TIMS) и геохимических особенностях циркона // Докл. Академии наук. 2017. 477. № 5. C. $595-599$.

7. Стешенко Е.Н., Николаев А.И., Баянова Т.Б., Дрогобужская С.В., Чащин В.В., Серов П.А., Лялина Л.М., Новиков А.И., Елизаров Д.В. Палеопротерозойский Колвицкий анортозитовый массив: новые данные о возрасте (U-Pb, ID-TIMS) и геохимических особенностях циркона // Докл. Академии наук. 2018. 479. № 2. C. 187-191.

8. Belousova E.A., Griffin W.L., O’Reilly S.Y., Fisher N.I. Igneous zircon: Trace element composition as an indicator of source rock type // Contributions to Mineralogy and Petrology. 2002. V. 143. P. 602-622.

9. Hanchar E., Hoskin P. Zircon / Reviews in Mineralogy \& Geochemistry. Washington: Mineralogical Society of America. 2003. V. 53. 500 p.

10. Jochum, K.P., Weis, U., Stoll, B., Kuzmin, D., Yang, Q., Raczek, I., Jacob, D.E., Stracke, A., Birbaum, K., Frick, D.A., Günther, D., and Enzweiler, J. Determination of Reference Values for NIST SRM 610-617 Glasses Following ISO Guidelines // Geostandards and Geoanalytical Research. 2011. 35. V. 4. P. 397-429.

11. Pearce N.J.G., Perkins W.T., Westgate J.A., Gorton M.P., Jackson S.E., Neal C.R., Chenery S.P. A compilation of new and published major and trace element data for NIST SRM 610 and NIST SRM 612 glass reference materials // Geostandards Newslett. 1997. 21. V. 1. P. 115-144.

12. Reishmann T., Brügmann G.E., Jochum K.P., Todt W.A. Trace element and isotopic composition of baddeleyite // Mineral and Petrology. 1995. V. 53. P.155-164.

13. Rubatto D., Scambelluri M. U-Pb dating of magmatic zircon and metamorphic baddeleyite in the Ligurian eclogites (Voltri Massif, Western Alps) // Contrib. Mineral Petrol. 2003. V. 146. P. 341-355.

14. McDonough W. F., Sun S-S. The composition of the Earth // Chemical Geology. 1995. V. 120. P. $223-253$.

15. Yuan H., Gao S., Liu X., Li H., Günther D., Wu F. Accurate U-Pb age and trace element determinations of zircon by laser ablation inductively coupled plasma-mass spectrometry //Geostand. Geoanal. Res. 2004. V. 28. P. $353-370$. 